\title{
Using models and spatial analysis to analyze spatio-temporal variations of food provision and food potential across China's agro-ecosystems
}

\author{
Qing Wang ${ }^{\mathrm{a}, \mathrm{d}, *}$, Xuehua Liu $^{\mathrm{a}}$, Tianxiang Yue ${ }^{\mathrm{b}}$, Chenliang Wang $^{\mathrm{b}}$, John P. Wilson $^{\mathrm{c}}$ \\ a School of Environment, Tsinghua University, Beijing, China \\ ${ }^{\mathrm{b}}$ Institute of Geographical Sciences and Natural Resources Research, Chinese Academy of Sciences, Beijing, China \\ c Spatial Sciences Institute, University of Southern California, Los Angeles, CA, USA \\ d State Environmental Protection Engineering Center for Industrial Pollution Supervising, Beijing, China
}

\section{A R T I C L E I N F O}

\section{Article history:}

Available online 22 January 2015

\section{Keywords:}

Population pressure

Food provision and potential

Spatio-temporal modeling and analysis

Agro-ecosystem

\begin{abstract}
A B S T R A C T
In order to better regionalize and discuss the rationality/irrationality of the spatial patterns China' food provision, food production and population data was collected and GIS spatial analysis and modeling methods were used. Multi-level spatial analysis and contrast between North and South China was carried out from three aspects: (1) Ecosystem food provision potential (EFPP). Step-by-step-modifying models were constructed to assess EFPP, parameters including solar radiation, temperature, humidity, topography, soil, and landuse. (2) Conversion ratio of the EFPP (CRFP), representing the ratio of actual food production to the EFPP. High EFPP and low CRFP means high remaining food potential for future exploration (or protecting, increasing). (3) Population pressure of food provision (PPFP). PPFP was calculated based on food production, population, nutrition ingredient, and consumption standards. High PPFP means food deficiency. Results: (1) The EFPP in South and Southeast China is much higher than in the North regions, while the CRFP is the opposite; this means the South and Southeast China has more remaining food potential to explore (or to protect). CRFP in Northeast China is the highest (81\%), indicating the food provision in Northeast China is approaching its maximum potential. In the future it is not wise to rely solely on food provision increases in North China, which may aggravate some problems like water shortage and ecosystem deterioration. (2) PPFP in the South and Southeast of China is much greater than in the North and has been rising, indicating that South and Southeast China have deficiency in food supply and is more and more dependent on food transportation from North China. It is necessary to preserve the fertile and high-yielding croplands as well as reclaim new food resources in the southern and eastern to improve its food self-sufficiency. From the above results, we can derive that the "North Grain to South" (NGS) pattern of China is irrational. This is in opposition to the present pattern of NGS but consistent with some other studies of domain experts, who also claim the NGS pattern may need adjustment.
\end{abstract}

(c) 2015 Published by Elsevier B.V.

\section{Introduction}

Food security is an important part of national security and social stability, but nowadays the world's food supply is under enormous threat. Despite continued growth in food production, there is still substantial numbers of undernourished people (FAO, 2012). In addition, humanity faces many threats such as poverty, pollution, land degradation, climate change, natural disasters (Battisti and

* Corresponding author at: School of Environment, Tsinghua University, Beijing, China. Tel.: +86 10 62794264/15011357139; fax: +861062794119.

E-mail address: wangq221@tsinghua.org.cn (Q. Wang).
Naylor, 2009; Funk and Brown, 2009) and water shortages (Hanjra and Qureshi, 2010), among others. Signs of heightened variability of food crop harvest are also of serious concern. Not surprisingly, food security has emerged as a worldwide challenge and has been the focus of considerable research during the past two decades (e.g. Duncan, 2002; Gilland, 2002; Godfray et al., 2010). Many commentators have argued that food security will deteriorate further unless leading countries can collectively mobilize to stabilize population, restrict the use of grain to produce automotive fuel, stabilize water tables and aquifers, protect cropland and conserve soils (e.g. Brown, 2008).

As the country with the largest population on Earth, China has attracted much concern around the world in terms of its ability to 
feed itself (referred to hereafter as its food provision). Some commentators have argued that China cannot produce sufficient grain to feed its 1.34 billion residents and that this will threaten global food security (e.g. Brown, 1995, 2011). This view has been contested by many researchers and also the Chinese government since China has been able to feed $22 \%$ of the world's people with just $7 \%$ of the world's croplands since the 1980s (IOSCC, 1996; Chen et al., 1998; Chen and Zhou, 2005). Rozelle and Rosegrant (1997), Yang and Li (2000) and Xu (2007), among others, have argued that China can maintain food security now and in the near future, by exploiting its agricultural comparative advantage, establishing stable trading relationships with the remainder of the world, and taking relevant countermeasures to protect and enhance its natural resources. Wu and Li (2002), Huang and Yang (2006), and Gong (2011) have all concluded that China's economic development and food consumption will bring no threats to other countries. Actually, in the recent 10 years, the food self-sufficiency of China has been above $95 \%$, and in 2012, China's total grain output reached 589.57 million tons, achieving continuous increase for nine years (Jin and Zhou, 2012; Zhao et al., 2012).

Certainly it will be a big challenge to feed such a large and ever increasing population with limited land and fast-developing industrialization and urbanization (Chen, 2007). Some fundamental problems with the food provision system and variations in regional development in China will likely add to the magnitude of this task. It is, therefore, necessary to perform more analysis to clarify the problems and challenges confronting China's major agroecosystems. China had experienced a significant harvest drop in late 1990s, mainly due to unfavorable weather conditions. However, the grain production has been increasing in the past 10 consecutive years, reaching record high of 601.93 million tons in 2013. The consumptive standard and diet structures are changing constantly too. Some work on food production potential (Cao et al., 1995; Tian, 2004; Deng et al., 2006), population carrying capacity (Chen, 2001), land use change and food security (Verburg et al., 2000; Yang and Li, 2000; Liu et al., 2005), climate change and future food supply (Xiong et al., 2007; Tao et al., 2009), soil degradation and future food security (Ye and Ranst, 2009), and water management, crop production and food security in China (Khan et al., 2009) has already been conducted. These study investigated the status and trend food security in China from different aspect, and some problems related to food security, like water shortage, soil degradation, climate change, were recognized and analyzed. However, little has been done on the spatio-temporal variations of food provision and food potential in China, and no research made comparison between the actual provision and potential, which is necessary for scientific decision-making on future food security.

In the past decades, China has been witnessing the change of food (mainly grain) transportation from "South Grain to North" to "North Grain to South" (NGS) (Yang, 1998; Zhang, 2000; Liu et al., 2007; Qu and Jiang, 2010), and the food provision center is moving northwards (Wang et al., 2012). The grain production in the North-East China accounted for $23.2 \%$ of the national total in 2012, while in 2003 the proportion was 17.7\%. The North-East China has become the region with fastest growth of grain production and largest of growth contribution of China (Zhao et al., 2012). The NGS pattern used to be considered a combination of advantages in regional resources and market demands. China's grain production growth more and more count on the northern regions. According to the Outline of the State's Medium- and Longterm Program on food security (2008-2020), by 2020, China's grain production capacity will increase 100 billion $\mathrm{kg}$, and $65 \%$ of the production-increasing task will count on the northern regions (The State Council of the People's Republic of China, 2008). This may aggravate some problems like water shortage and ecosystem deterioration in North China. However, few studies have examined the relationships between spatio-temporal variations in food nutrition, population carrying capacity and population pressure. As defined by the World Food Summit, food security exists when all people, at all times, having access to sufficient, safe and nutritious food to meet their dietary needs and food preferences for an active and healthy life (FAO, 2009). Following this definition, we focus on three aspects related to the study of food security in China. First, the food nutrition index is very important in evaluating the degree of food security. Recently in China, the living standard for many residents has improved and the food nutrition consumption structure has changed (Feng and Chen, 1992). Therefore, besides the traditional indices like grain productivity, agricultural acreage, and per-capita food occupancy, it is also important to estimate the food provision, food potential and food security situation with food nutrition indices (Lu and Liu, 1993; Lu, 2003; Tian, 2004). Second, the population size is closely related to the food security of a certain region, as the population size and the consumption patterns and preferences help to determine the food demand or need. Third, the food provision potential of the agro-ecosystem is the upmost limit of food production in a certain region over a certain period, which is determined by the climate, landscape, soil and other factors.

In this study, we document the spatio-temporal variability in nutrition indices, the population pressure of food provision (PPFP) and the conversion ratios of food potential (CRFP) to evaluate the state of food security across the major regions and agro-ecosystems in China. The remainder of the article is divided into three major sections. Section 2 describes the various spatial analysis methods and geospatial data sources used in our analysis. Section 3 presents the major results with the help of a series of maps and tables and discusses their broader significance. Section 4 concludes by summarizing the major findings and offering some suggestions for future work. We believe the approach we have taken will provide a more detailed and robust view of China's future food security prospects than the aforementioned works.

\section{Methods}

\subsection{Data and data pre-processing}

In this study, agro-ecosystem is defined as the cropland, in which all kinds of grain and oil crops are planted. In order to analyze the food provision situation of China's agro-ecosystems, we first obtained food production data (county level) compiled from surveys by the Chinese Academy of Agriculture Sciences (CAAS) from 1980 to 2005. (For the data availability, we failed to make the calculation and analysis for the years after 2005). These data covered the five main crops in China, i.e. rice, maize, wheat, soybean and oilseeds, and the nutrition composition of each crop food was calculated referring to the 2004 food composition data reported by Yang (2005). We next obtained the county-level census data of population for the period 1980-2005 from the Chinese Academy of Agriculture to calculate the PPFP. Finally, we utilized the food potential maps generated by Tian (2004) and Yue et al. (2008), as will be discussed in more detail below, to calculate the CRFP.

Before the calculations were performed, all of the data were carefully checked by comparing to the statistic data and other resources of food producing data (Rural Survey Organization, National Bureau of Statistics, 2000; National \& Local Bureau of Statistics of Each Province, Autonomous Region, Municipality in China, 2000-2005), and evident erroneous values were alternated by the average value of the adjacent two or four years. To perform the spatial analysis, we linked the food production and population data summarized in Excel tables to the county map data stored in an Esri shapefile format, and examined the spatial patterns of crop production and population using ArcGIS ${ }^{\mathrm{TM}}$ (Redlands, CA, USA). Given 
Table 1

Nutrition composition of different food crops (unit/100 g) (Yang, 2005).

\begin{tabular}{llcc}
\hline Food crop $(l)$ & \multicolumn{3}{l}{ Nutrition $(j)$} \\
\cline { 2 - 4 } & 1. Calories/kcal & 2. Protein/g & 3. Fat/g \\
\hline 1. Rice & 346 & 7.4 & 0.8 \\
2 Wheat & 317 & 11.9 & 1.3 \\
3. Maize & 335 & 8.7 & 3.8 \\
4. Soybean & 359 & 35.0 & 16.0 \\
5. Oilseeds & 298 & 12.0 & 25.4 \\
\hline
\end{tabular}

more than 20 years of data, some boundaries as well as the names or IDs of counties changed, so we had to check and search through a variety of reference documents and maps to modify them and ensure that the attribute data matched the map data.

\subsection{Calculation of the food nutrition provision}

The production of the five main food crops in China was converted to food nutrition provision, measured in terms of calories, protein and fat. Two advantages of using nutrition are that: (1) all kinds of food crops from various ecosystems can be converted into uniform parameters like food calories, protein and fat for comparison; and (2) we can use nutrition to calculate the population pressure on food production since some available standards concerning people's daily food nutrition requirements are known (e.g. Lu, 2003).

We therefore calculated the food production of cropland in terms of calories, protein and fat using Eq. (1) (Yue et al., 2010), and got the food nutrition provision of each spatial unit: every county and the whole China.

$P_{i j}=\sum_{l=1}^{5} M_{i l} \times Q N_{j l}$

where $P_{i j}$ is the total nutrition produced on farmland in county $i$; $l$ has values from 1 to 5 representing the five crops: rice, wheat, maize, soybean and oilseeds; $M_{i l}$ is the total production $(\mathrm{kg})$ of crop $l$ in county $i ; j$ has values of 1,2 and 3 representing respectively, calories (kcal), protein $(\mathrm{kg})$ and fat $(\mathrm{kg})$; and $Q N_{j l}$ is the conversion factor from crop $l$ to either calories, protein or fat (written here as j) (Table 1).

\subsection{Calculation of the population pressure of food provision (PPFP) in China}

China's food security goals are intimately linked to development because living standards would go from primary well-to-do to full well-to-do and then well-off with development, and the nutrition consumption standards are different under different living levels (Table 2) (Lu and Liu, 1993; Lu, 2003; Yue et al., 2008).

In this study, PPFP is a value that can reveal the population pressure of food provision in a region (or county); it is the ratio of the actual population size compared with the population that the actual food provision can supply in a region. Based on food nutrition consumption standards under different living levels, we calculated the

Table 2

Nutrition consumption standards among different living standards (per capita per day) (Lu and Liu, 1993; Lu, 2003; Yue et al., 2010).

\begin{tabular}{llll}
\hline \multirow{2}{*}{ Living standards } & \multicolumn{2}{l}{ Nutrition consumption } & \\
\cline { 2 - 4 } & Calories/kcal & Protein/g & Fat/g \\
\hline Primary well-to-do & 2289 & 77 & 67 \\
Full well-to-do & 2295 & 81 & 67.5 \\
Well-off & 2347 & 86 & 72 \\
\hline
\end{tabular}

population that can be supported by each food nutrition class under different living levels with Eq. (2):

$P_{P o p}=P_{i j} / 365 / F_{j k}$

where $P o p_{i j}$ represents the population supported by food nutrition $j$ in county $i$; $P_{i j}$ is the provision of food nutrition $j$ in county $i$; and $F_{j k}$ is the daily per capita consumption of food nutrition $j$ under living standard $k$.

The PPFP index was then calculated using Eq. (3):

PPFP $_{i j}=\frac{\text { Pop }_{i}}{\text { Pop }_{i j}}$

where the $P P F P_{i j}$ represents the PPFP of food nutrition $j$ in county $i$; $P_{o p}$ is the actual population in county $i$; and $P_{0} p_{i j}$ is the population that can be supported by food nutrition $j$ in county $i$.

\subsection{Calculation of the conversion ratio of the food potential (CRFP) in China}

CRFP is the ratio of actual food provision and the food potential, which means the degree of the exploitation of the food potential in a certain region. The spatial pattern of CRFP in China was calculated using Eq. (4) below and the spatial analysis tools in ArcMap:

$\operatorname{Tr}_{i}=\frac{P_{a i}}{P_{0 i}}$

where $T r_{i}$ represents the CRFP of region $I, P_{a i}$ represents the present food provision, $P_{0 i}$ is the food potential, and $i$ refers to one of the six regions (i.e. North, Northeast, East, Central-South, Southwest, Northwest) of China.

This is a marked improvement over previous studies by Tian (2004) and Yue et al. (2008). In their study, surface models are developed for simulating the food provision capacities of cropland in China (Eq. (5)).

$Y=Q \cdot f(Q) \cdot f(T) \cdot f(W) \cdot f(S) \cdot f(M) \cdot H I \cdot A_{f o o d}$

where $Y$ is the grain yield per unit area $\left(\mathrm{kg} / \mathrm{hm}^{2}\right) ; H I$ is the harvest index (\%); $A_{\text {food }}$ is effective area $\left(\mathrm{hm}^{2}\right)$ of cultivated land; $f(Q)$ is photosynthetic potential $\left(\mathrm{kg} / \mathrm{hm}^{2}\right) ; Q$ is solar radiation $\left(\mathrm{j} / \mathrm{cm}^{2}\right) ; f(T)$, $f(W), f(S)$, and $f(M)$ are the effective coefficients (\%) of solar radiation, temperature, soil moisture content, soil fertility, and agricultural production input, respectively (Tian, 2004; Yue et al., 2008).

They assumed balanced food nutrition production and consumption systems and estimated that China's terrestrial agroecosystems could supply food for 3.068 billion people under primary well-to-do living standards, 2.426 billion under full wellto-do living standards, and 2.274 billion under well-off living standards. The spatial pattern of population-supporting potential in China from these earlier studies is summarized in Fig. 1. This map also shows the six regions and several of the important rivers and other landscape features found in China that will be referred to later in this article.

\section{Results}

\subsection{Spatial patterns of food production}

Food production across China's major agro-ecosystems has increased since the 1980 s and the spatial pattern of food production in 2005 is summarized in a series of maps in Fig. 2. The Northeast Plain, North China Plain, Sichuan Basin, and middle-lower reaches of the Yangtze River region (whose approximate locations are shown in Fig. 1) have a high grain yield (Fig. 2a). 


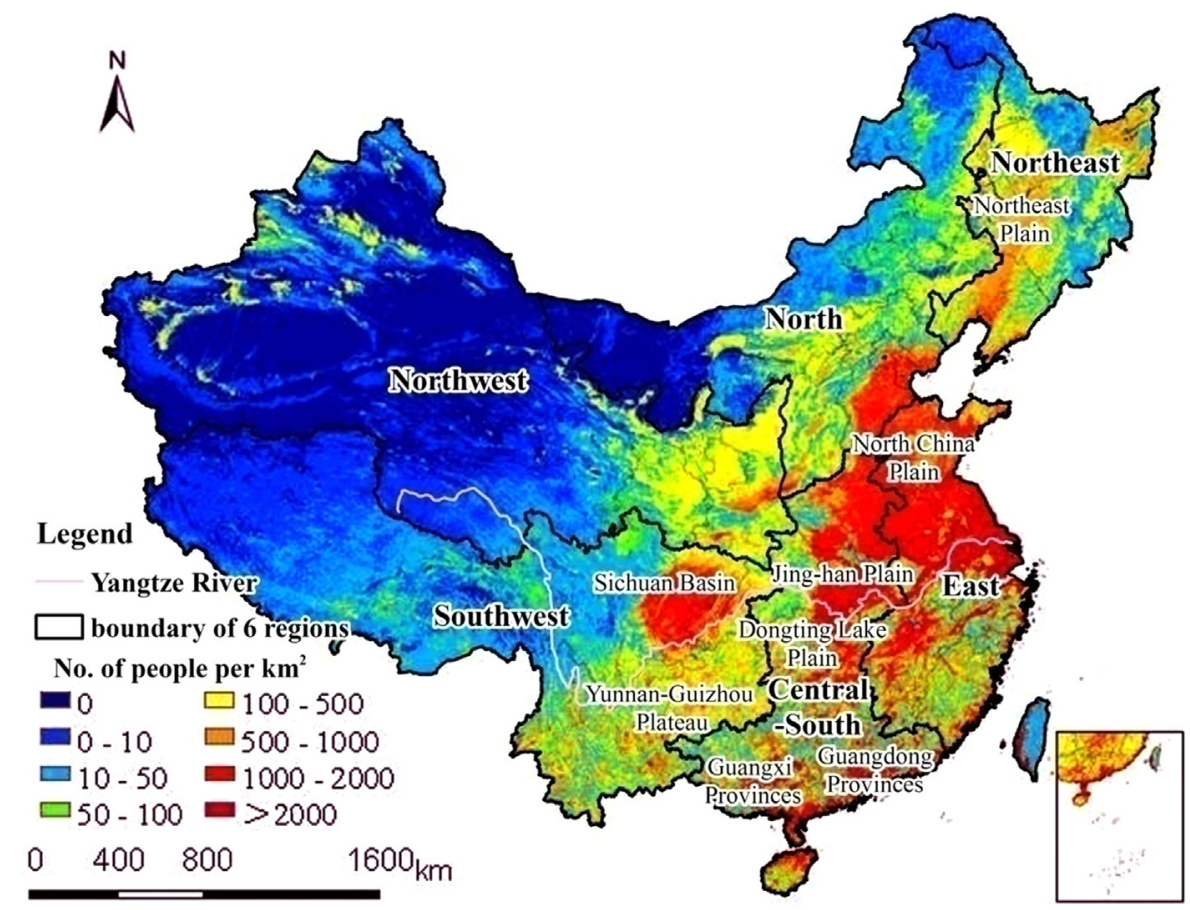

Fig. 1. Population-supporting potential of China's agro-ecosystems under well-off living standards (Tian, 2004).

\subsection{Spatial patterns of total food nutrition provision}

The total food nutrition provision of farmland in China in 2005 was $1.48 \times 10^{15} \mathrm{kcal}$ of calories, $4.57 \times 10^{7} \mathrm{t}$ of protein and $1.86 \times 10^{7} \mathrm{t}$ of fat - can support the consumption of 1.726 million, 1.547 million and 753 million persons, respectively under full wellto-do living conditions. Given the current population of 1.34 billion in 2012, there is sufficient food measured in terms of calories and protein to feed China's population at the full well-to-do living standard. However, there is a great shortage in terms of fat.

\subsection{Spatial patterns of population pressure of food provision}

The spatial pattern of population pressure of food provision is shown in Fig. 3. Among the three nutrition types, the PPFP for calories is the least problematic (Fig. 3a). The PPFP of calories is less than 1.0 in approximately $70 \%$ of China's counties indicating that the provision of food calories in these counties is abundant and more than sufficient to meet current needs. However, a few counties located in the developed coastal regions of East China, the east part of South-West China
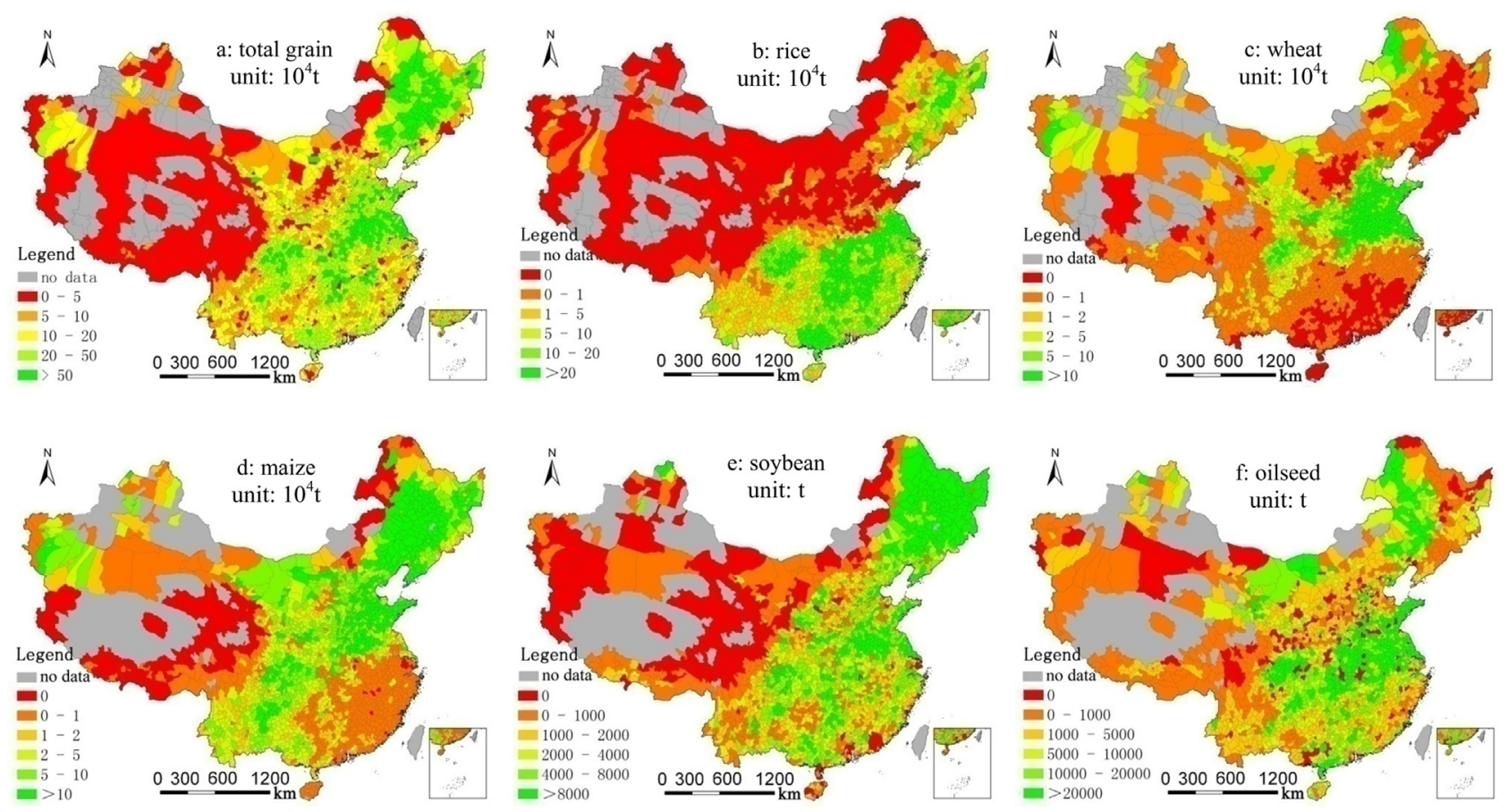

Fig. 2. Spatial patterns of production of grains and the five major food crops considered in this study in 2005 . 

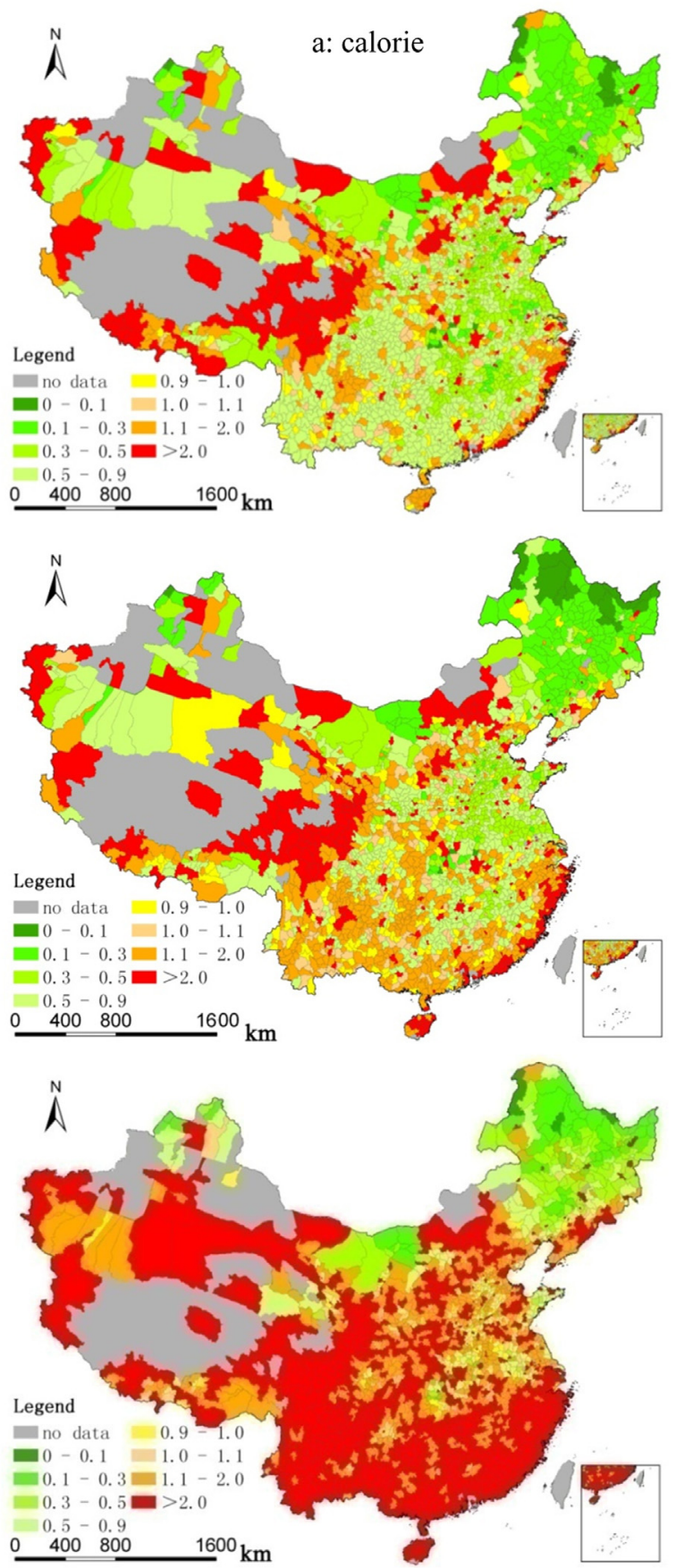

Fig. 3. Spatial patterns of population pressure of food provision (PPFP) in 2005.

and the southeast part of North-West China have food calorie deficiencies.

The PPFP of protein in China is higher on average than that of food calories. The PPFP of protein is below 1.0 in 56\% of China's counties and the maps reproduced in Fig. $3 a$ and $b$ shows food protein provision shortfalls in the southern parts of Central-South and South-West China as well as in those areas noted earlier that experience shortfalls in food calorie provision.

The PPFP of fat is highest of all with nearly four of every five counties (79\%) showing PPFP of fat ratios above 1.0, which means of course that food fat provision is deficient in these counties. Food fat provision is adequate in North-East China and isolated areas in North-West China, the north part of North China, the North China Plain and a few counties in the middle-lower reaches of the Yangtze River region (Fig. 3c).
Table 3

Conversion ratio of food potential (CRFP) of each of China's six major regions in 2005 (\%).

\begin{tabular}{lllll}
\hline Regions & Total grain & Food calories & Food protein & Food fat \\
\hline North & 65.0 & 48.0 & 55.4 & 57.57 \\
Northeast & 81.2 & 69.9 & 84.6 & 98.7 \\
East & 37.6 & 33.5 & 33.4 & 32.1 \\
Central-South & 37.1 & 32.5 & 31.4 & 29.3 \\
Southwest & 40.8 & 29.7 & 27.7 & 26.1 \\
Northwest & 49.9 & 37.1 & 41.4 & 35.2 \\
\hline
\end{tabular}

The three maps reproduced in Fig. 3, considered as a whole, show that the PPFP in North-East China is the lowest, indicating surplus food provision. Low PPFP ratios can also be seen in the sparsely populated regions of South-West China and North-West China, where the food demand is low. Some parts of the NCP and the middle-lower reaches of the Yangtze River region, where population density is high but food production is also high due to favorable hydrothermal conditions are also characterized by abundant food provision. The maps also show how South China now relies on food from North China to feed its growing population.

The coastal regions in South-East China and the Beijing-Tianjin region in North China also have high PPFP ratios. Some counties in the eastern parts of South-West China and southern parts of Central-South China show high PPFP ratios for food fat, although the PPFP ratios for food calories and protein indicate these components are abundant (Fig. 3a and b). This state of affairs illustrates the longstanding imbalance in the food nutrition provision structure noted earlier.

\subsection{Regional characteristics of the conversion ratio of food potential}

The regional statistics of CRFP from 1980 to 2005 are summarized in Fig. 4. The purple bars show that Central-South and East China have the highest grain potential, due to their good hydrothermal conditions, followed by South-West China, NorthEast China, and North China (Fig. 4a). North-West China has the lowest grain potential given poor conditions for supporting grain production.

Table 3 shows the CRFP patterns in the six major regions of China in 2005 as an example. Presently, the region with the highest CRFP is North-East China, which has been China's "North Barn" for almost half a century. The grain production potential conversion ratio in North-East China reached $81.2 \%$ in 2005; with much lower CRFP values in the other regions.

The East China and Central-South China regions have the lowest CRFP due to two factors: firstly, the water and temperature conditions are better so the food potential, the denominator of the CRFP function, is larger; and secondly, because many farmers nowadays prefer to find a job in the city or they plant cash crops to earn more money, which leads to low or decreasing multi-cropping index (MCI) and acreages. The latter threatens China's long-term food security and the government has been taking measures to resolve it (Liu et al., 2005). Policies such as agricultural tax remittances and various kinds of agricultural subsidies have been established and carried forward since the early 2000s for example.

The spatial patterns of the potential measured in terms of food calories, food protein and food fat are similar to that of grain potential (Fig. 4b-d). The East and Central-South China regions have much higher values than the other regions; followed by South-West China and then North China and North-East China, with North-West China lower again.

In general, the spatial patterns of the conversion ratio for the three food nutrition classes are similar - the highest rates are found in North-East China, followed by North, Northwest, East and 

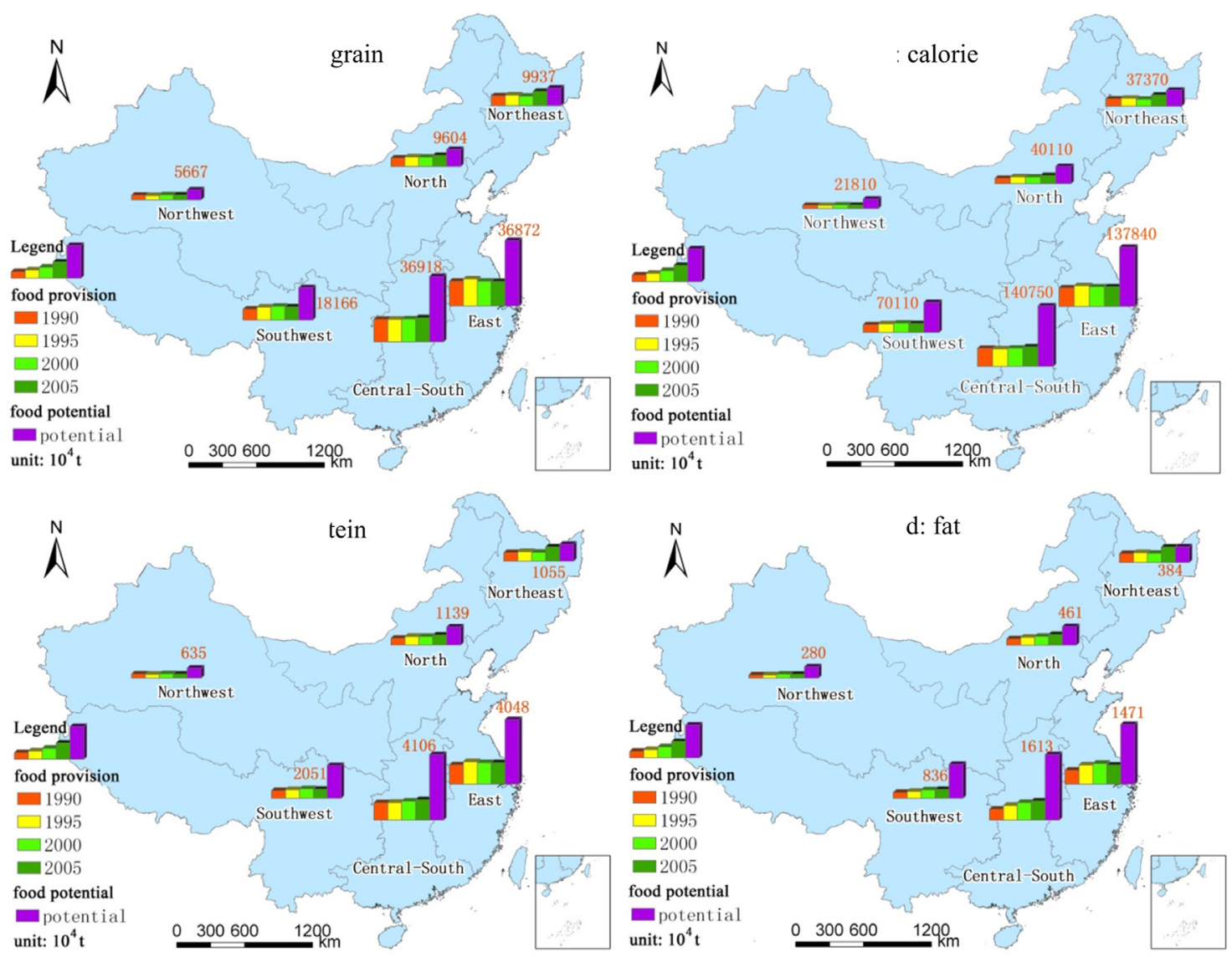

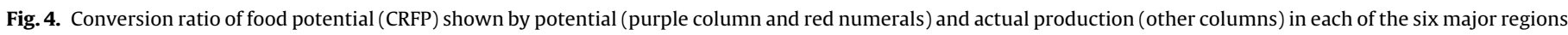
of China.

Central-South China, with South-West China bringing up the rear. We compared north and south China and found that, in the north, the food provision potential is relatively low whilst the conversion ratio is relatively high, whereas the south shows the opposite result, with high potential but low conversion ratios. However, this result partially hides the fact that large expanses of high-yielding cropland in south and South-East China have been gradually occupied by buildings or other land uses every year for the past several decades. The farmers have switched the cropland into orchard in some instances or found work in nearby cities to earn higher incomes, leaving their cropland abandoned and/or switching to the cultivation of two crops in place of three crops or one crop in place of two crops per year. These trends suggest that, in the future, China will need to pay more attention to the food provision of the southern regions and that measures may need to be taken to protect the high-yielding croplands in South China from urbanization.

\section{Conclusions and discussion}

The results of the aforementioned spatio-temporal analysis lead to three major conclusions about China's food production and consumption systems.

(1) The food nutrition provision structure of China's agro-ecosystems is unbalanced - the food fat shortages and food calorie and protein surpluses are major problems for most of the counties experiencing high population pressure. The food fat deficiency is therefore nationwide issue in China. This shortfall has been a challenge for China for several years and although countermeasures to optimize the food provision structure have been proposed, further studies and solutions are still needed because China still counts heavily on imported oilseeds. China needs to optimize the present cropping and breeding structure to change the nutrient, energy and water fluxes in the food-producing ecosystems, for example, to grow more oilseeds like soybean, rapeseed and peanuts, and to breed more fat-providing cattle to fill the gap between oil/fat demands and provision, although the present fact is, the price of importing soybean is much lower than domestic growing, and farmers lack enthusiasm to grow soybean. Therefore the dependence on import is more and more obvious for the last decades. In recent years, some countermeasures like soybean subsidies have been taken to solve this problem. This can, to some extent, help to stabilize the soybean price and maintain national food security (Ni, 2013).

(2) The population pressure is lower in North China and North-East China than that in South China and East China. There are three sets of factors contributing to this outcome: (1) the rapid economic development in South China and East China has spawned high rates of cropland conversion; (2) the rapidly growing population has increased local food demand; and (3) cropland and water resources has been explored rapidly and excessively in North China and North-East China in the last decades, so the food producing in North China and North-East China increase rapidly, and the food provision here has been growing faster than the population.

(3) The NGS pattern of China need more consideration. According to our results, the food potential in the South China is much larger than in the North China, while the conversion ratio is exactly the opposite. There used to be large areas of plain with high quality soil in North China and North-East China, and the untouched arable land resources and ground water have been explored for the last decades, and also thanks to the using of pesticides 
and fertilizers, the production of maize and wheat kept increasing fast in North China and North-East China (China Statistical Yearbook, 2008, 2009). Indeed, after so many years of excessive exploring, the actual food provision in North-East China is approaching its maximum potential and if high-intensity cropping continues, the continued productivity of these croplands will be threatened for water scarcity and land degradation. Natural forces coupled with foolhardy cultivation means that the soil erosion problems on the fertile black land soils are getting more and more acute. According to a study in 2009, the surface of the black land soils in North-East China is being lowered at rates of $0.3-1.0 \mathrm{~cm} \mathrm{yr}^{-1}$, and the organic matter content of these soils has been decreasing as well, implying a declining trend in the food production capacity (Yu and Zhang, 2004; $\mathrm{Xu}$ et al., 2010). The food production capacity of the North China Plain is also threatened because groundwater is mined and the water table is declining fast, causing many problems for the local environment (Shi et al., 2011.). The government and local farmers in the North and North-East China regions need to improve water supply and reduce soil erosion to ensure sustainable food provision on the North-East Plain and North China Plain. In North China, other ecological problems might be and have been caused like desertification, ground subsidence, pollution, wetland shrinking, and biodiversity decline. While in South China, there is, on the other hand, still great food potential remaining to be explored, according to the evaluating results of food potential and the CRFP. However, the rapid urbanization and economic development have caused the decreasing of cropland and declining of multi-cropping index in South China and South-East China. Therefore, food provision in South China and South-East China has decreased in recent years, despite the increases in yields brought by progress in agricultural science and technology (Yan et al., 2005). While the facts revealed in this study suggests that, for the future, China will not achieve its goal of food security relying solely on food provision increases in North China and it will therefore need to preserve the fertile and high-yielding croplands as well as reclaim new food resources in the southern and eastern parts of China. However, the ongoing urbanization on the highquality arable land in South and Southeast China is irreversible, which we should remind the policymakers to see this and optimize the developing plan. This point of view is also consistent with some other studies carried out by the domain experts (Liu et al., 2007; Pang, 2011). They affirmed that, unless the agricultural water-saving technology greatly improved, over-reliance on the northern farmland to achieve the yield-increasing goals will be at the cost of eco-environment deterioration and sacrificing the capacity for sustainable development of the northern region. The NGS pattern is necessary to be analyzed with further and in-depth study and adjustments should be made, for sustainable food security in China (Liu et al., 2007; Pang, 2011). The findings could provide scientific basis from new perspective for decision-making.

(4) The calculation in this study are based on simple equations and ecological mechanism models (the surface models for simulating the food provision capacities of cropland in China), and actual production data. The data was supported by the Institute of Agricultural Resources and Regional Planning, CAAS, and they have yearly work on agricultural census and survey in China. And other data was collected from the Statistical Yearbooks. All the data was reliable. However, because the cooperation finished and the financial support on this project ended, we failed to get these data in recent years. Food security is a complex issue, which is more social than natural, although food provision is based on nature and ecosystem. This study attempt to combine the natural factors (solar radiation, temperature, soil, etc., for the natural ecosystem capacity) and social factors (population, food nutrition consumption standards, living levels) to analyze the food security issue in China from new aspect, using ecological modeling methods as well as real data. Our models are relatively simple to analyze such complex issue. Therefore, drawbacks of our methods and the models are inevitable. We focused on the five main food crops produced by China's terrestrial agro-ecosystems. Similar production data were not available for other crops and food sources, like sorghum, potato, seafood, dairy, fruit and so on. While the potential models evaluated all the food potential in China's agro-ecosystems. However, it is the case that the China's total food provision would have been higher and the PPFP would have been lower if all of these other food sources had been included in the calculation.

\section{Acknowledgements}

This work is supported by the China Postdoctoral Science Foundation funded project (2012M520011 and 2013T60101), the China National Science Fund for Distinguished Young Scholars (40825003), and by the National Basic Research Priorities Program (2010CB950904) of Ministry of Science and Technology of the People's Republic of China. We also thank the Institute of Agricultural Resources and Regional Planning, CAAS, for data support.

\section{References}

Battisti, D.S., Naylor, R.L., 2009. Historical warnings of future food insecurity with unprecedented seasonal heat. Science 323 (5911), 240-244.

Brown, L.R., 1995. Who Will Feed China? Wake up Call for a Small Planet. Earthscan Publications, Washington, DC.

Brown, L.R., 2008. Plan B Updates: World Facing Huge New Challenge on Food Front - Business-as-Usual not a Viable Option. Earth Policy News, Available from: http://www.earth-policy.org/plan_b_updates/2008/update72 [accessed 16.04.08].

Brown, L.R., 2011. Can the United States Feed China? The Washington Post, Sunday Outlook, Available from: http://www.washingtonpost.com/opinions can-the-united-states-feed-china/2011/02/28/AB7mXrQ_story.html [accessed 13.03.11]

Cao., M.K., Ma, S.J., Han, C.R., 1995. Potential productivity and human carrying capacity of an agro-ecosystem: an analysis of food production potential of China. Agric. Syst. 47, 387-414.

Chen, B.M., 2001. Comprehensive Productive Capacity and Population-Carrying Capacity of Agricultural Resources in China. China Meteorological Press, Beijing (in Chinese).

Chen, J., 2007. Rapid urbanization in China: a real challenge to soil protection and food security. Catena $69,1-15$.

Chen, B.M., Zhou, X.P., 2005. Analysis on the grain self-sufficient ratio and the safe baseline of cultivated land in China. Econ. Geogr. 25, 145-148 (in Chinese).

Chen, B.M., Chen, N.P., Chen, A.N., 1998. Who Are Feeding the U.S.? The Commercial Press, Beijing (in Chinese).

Deng, X.Z., et al., 2006. Cultivated land conversion and potential agricultural productivity in China. Land Use Policy 23, 372-384.

Duncan, R.C., 2002. Food security and the world food situation. In: Gardner, B.L., Rausser, G.C. (Eds.), Handbook of Agricultural Economics, 2, 1st ed. Elsevier, Oxford, pp. 2191-2213.

FAO, 2009. The State of Food and Agriculture: Livestock in the Balance. Food and Agriculture Organization of the United Nations, Rome.

FAO, 2012. The State of Food Insecurity in the World. Food and Agriculture Organization of the United Nations, Rome.

Feng, Z.M., Chen, B.M., 1992. Dietary levels of future population in China. Bull. Chin Acad. Sci. 3, 21-26 (in Chinese).

Funk, C.C., Brown, M.E., 2009. Declining global per capita agricultural production and warming oceans threaten food security. Food Secur. 1, 271-289.

Gilland, B., 2002. World population and food supply: can food production keep pace with population growth in the next half-century? Food Policy 27, 47-63.

Godfray, H.C.J., et al., 2010. Food security: the challenge of feeding 9 billion people. Science 327 (5967), 812-818.

Gong, P., 2011. China needs no foreign help to feed itself. Nature 474 (7349), 7.

Hanjra, M.A., Qureshi, M.E., 2010. Global water crisis and future food security in an era of climate change. Food Policy 35, 365-377.

Huang, J.K., Yang, J., 2006. The rise of China's economy and food and energy security, and the development of world economy. Manage. World 1 (67-74), 82 (in Chinese).

IOSCC (Information Office of the State Council of the People's Republic of China) 1996. The Grain Issue in China. Chinese Government White Paper, Beijing. 
Jin, Z., Zhou, S.Y., 2012. Bumper crops mean China can feed itself. China Daily, Available from: http://www.chinadaily.com.cn/cndy/2012-12/26/content_ 16055012.htm [accessed 26.12.12].

Khan, S., Hanjra, M.A., Mu, J., 2009. Water management and crop production for food security in China: a review. Agric. Water Manage. 96, 349-360.

Li, X.C., et al., 2008. China Statistical Yearbook. China Statistics Press, Beijing (in Chinese).

Li, X.C., et al., 2009. China Statistical Yearbook. China Statistics Press, Beijing (in Chinese).

Liu, J.Y., et al., 2005. Spatial and temporal patterns of China's cropland during 1990-2000: an analysis based on Landsat TM data. Remote Sens. Environ. 98, $442-456$.

Liu, Y.J., et al., 2007. The change of the main regions for China's food grain production and its implications. Resour. Sci. 29 (2), 8-14 (in Chinese).

Lu, L.S., 2003. Food and Nutrient for Development in China. China Agriculture Press, Beijing (in Chinese).

Lu, L.S., Liu, Z.C., 1993. Long-term Strategy of China's Food Development. China Agriculture Press, Beijing (in Chinese).

National \& Local Bureau of Statistics of Each Province, Autonomous Region, Municipality in China, 2000-2005. National \& Local Statistical Yearbook in China from 2000 to 2005. China Statistics Press, Beijing (in Chinese).

Ni, H.X., 2013. Research on the Agricultural Support Policy in China. No. 47 Report of International Centre for Trade and Sustainable Development. http://ictsd.org/ i/publications/162727/

Pang, H.C., 2011. China's grain production should be expansion in the South and suppression in the North. Beijing Observ. 5, 35 (in Chinese).

Qu, Z., Jiang, Y.Z., 2010. The step of sending grains from the North to the South in China is speeding up. Agric. Econ. 02, 29-32 (in Chinese).

Rozelle, S., Rosegrant, M.W., 1997. China's past, present, and future food economy: can China continue to meet the challenges? Food Policy 22, 191-200.

Rural Survey Organization, 2000. National Bureau of Statistics. Agricultural Statistical Data from 1949 to 1999 in China. China Statistics Press, Beijing (in Chinese).

Shi, J.S., et al., 2011. Assessment of deep groundwater over-exploitation in the North China Plain. GeoSci. Front. 2 (4), 593-598.

Tao, F.L., et al., 2009. Climate change, land use change, and China's food security in the twenty-first century: an integrated perspective. Clim. Change 93, 433-445.

The State Council of the People's Republic of China, 2008. The Outline of the State's Medium- and Long-term Program on food security (2008-2020), Available from: http://www.gov.cn/jrzg/2008-11/13/content_1148414.htm [accessed 13.11.08] (in Chinese).
Tian, Y.Z., (Unpublished Ph.D. Dissertation) 2004. Assessment of Potential Food Provisioning Services of Terrestrial Ecosystems in China Based on Grid-cells. Institute of Geographical Sciences and Natural Resources Research, Chinese Academy of Sciences (in Chinese).

Verburg, P.H., Chen, Y., Veldkamp, T., 2000. Spatial explorations of land use change and grain production in China. Agric. Ecosyst. Environ. 82, 333-354.

Wang, Q., et al., 2012. Spatial-temporal variations of food provision in China. Procedia Environ. Sci. 13, 1933-1945.

Wu, S.H., Li, R.S., 2002. Food demand, ensure and countermeasures for China in the next 30 years. Prog. Geogr. 21, 121-129 (in Chinese).

Xiong, W., et al., 2007. Climate change and critical thresholds in China's food security. Clim. Change 81, 205-221.

Xu, S.W., 2007. The situation and countermeasures of food security in China. Forum Sci. Technol. China 11 (116-119), 131 (in Chinese).

$\mathrm{Xu}, \mathrm{X} . Z$., et al., 2010. Soil loss and conservation in the black soil region of Northeast China: a retrospective study. Environ. Sci. Policy 13, 793-800.

Yan, H.M., Liu, J.Y., Cao, M.K., 2005. Remotely sensed multiple cropping index variations in China during 1981-2000. Acta Geogr. Sin. 60 (4), 559-566 (in Chinese)

Yang, H., 1998. Trends in China's regional grain production and their implications. Agric. Econ. 19 (3), 309-325 (in Chinese).

Yang, Y.X., 2005. China Food Composition 2004. Peking University Medical Press, Beijing (in Chinese)

Yang, H., Li, X., 2000. Cultivated land and food supply in China. Land Use Policy 17, 73-88.

Ye, L.M., Ranst, E.V., 2009. Production scenarios and the effect of soil degradation on long-term food security in China. Glob. Environ. Change 19, 464-481.

Yu, L., Zhang, B., 2004. The degradation situations of black soil in China and its prevention and counter measures. J. Arid Land Resour. Environ. 18 (1), 99-103 (in Chinese).

Yue, T.X., et al., 2008. Surface modeling of human carrying capacity of terrestrial ecosystems in China. Ecol. Model. 214, 168-180.

Yue, T.X., et al., 2010. Change trends of food provision in China. Glob. Planet. Change $72,118-130$.

Zhang, L.C., 2000. Food distribution change in China and its reasons. Resour. Environ. Yangtze Basin 9 (2), 221-228 (in Chinese).

Zhao, J.P., et al., 2012. China's grain production reached a new high Farmer Daily, Available from: http://www.farmer.com.cn/xwpd/btxw/201212/ t20121226_789820.htm [accessed 26.12.12] (in Chinese). 